\title{
Re-Preparing the Secondary Physics Teacher
}

Fred Stein

American Physical Society

\section{Introduction}

This case study describes a successful and on-going program begun at Colorado State University (CSU) in 1994. It dramatically improved the preparation of secondary science and mathematics teachers through the revision of targeted science, mathematics and education courses, and the expansion and enrichment of field experiences.

From 1994-1999, CSU was the lead institution in a project called the Rocky Mountain Teacher Education Collaborative, one of the sites of the NSF-supported Collaboratives for Excellence in Teacher Preparation. CSU worked in concert with two other universities and three community colleges (University of Northern Colorado, Metropolitan State College of Denver, Community College of Denver, Aims Community College and Front Range Community College). The program continues to impact all prospective science and mathematics teachers at CSU (including chemistry, geology, biology and mathematics teachers) and many faculty members. Key to the success of the programs was the institutionalization of the following program elements. (1) A long-term, active collaboration between the science and mathematics departments and the CSU school of education; (2) A productive Teacher-in-Residence program that is used as a "reality check" for reform; (3) The redesign of content and pedagogy for targeted science and mathematics courses based on results from science and mathematics education research; (4) The integration of learning theory, teaching methods, and science and mathematics content through a revised and team-taught science methods course; and (5) The participation of science and mathematics faculty in the assignment and supervision of practicum and student-teaching experiences.

\section{Background and Goal}

From 1984, beginning with A Nation at Risk, through 1996, with Shaping the Future 1 and recently with To Touch the Future: Transforming the Way Teachers are Taught, ${ }^{2}$ national reports have decried the inadequate preparation 
and lack of competency of new science teachers at all levels $\mathrm{K}-12$. If it is true that "teachers teach as they were taught," then the vision for improving physical science and physics teaching and learning in $\mathrm{K}-12$ should be that universities model effective teaching/learning approaches in their science courses for both majors and non-majors. This was the vision that drove the program discussed in this case study. The four-year institutions in this project encouraged science and mathematics departments to collaborate with their departments of education to plan and improve the science preparation of future secondary science teachers through the revision of targeted courses and enriched field experiences. Ultimately, the goal was to produce better-prepared science and mathematics teachers who were committed to the objectives of the national reform movements such as the National Science Education Standards (NRC), the Benchmarks from Project 2061 (AAAS) and the three volumes of Standards from the National Council of Teachers of Mathematics (NCTM).

\section{Project Activities}

Over five years, the following components were put in place:

- A long-term, active collaboration between the physics, chemistry, biology, geology and mathematics departments, the school of education, the local two-year college and the local school community

- A productive Teacher-in-Residence (TIR) program that was used as a "reality check" for reform

- The redesign of content and pedagogy for targeted science and mathematics courses by faculty based on results from science and mathematics education research and utilizing appropriate technologies

- The integration of learning theory, teaching methods and science content through the revised and team-taught science and mathematics methods courses

- The participation of science and mathematics faculty in the assignment and supervision of practicum and student teaching experiences.

\section{Project Components \\ Teachers in Residence}

The TIR brought the knowledge and experience of managing a student-centered science class, assisted faculty in revising targeted science and mathematics courses and helped team-teach the science and mathematics methods courses. The TIR at CSU was housed in the Center for Science, Mathematics \& Technology Education (CSMATE) facility but also worked with the school of education and the local schools. The TIR provided continuity between the science and mathematics methods courses, the science courses and the activities in the local schools. The university reimbursed the school district for the cost of the TIR's replace- 
ment. Later, CSMATE provided the TIR with a mini-grant for classroom supplies when they returned to the classroom. The TIR consulted with preservice teachers and provided a realistic understanding of what is being taught and how it is being taught in the schools. The TIR offered valuable contacts with local teachers and school districts that significantly improved practicum activities and the placement of student teachers.

Professor Sanford Kern reflects on his experience working with TIR:

"Two Teachers-in-Residence were involved in the physics classes, one each during the 1996/97 and 1997/98 academic years. Their presence was invaluable. They were able to communicate directly to me about the backgrounds, knowledge base, and likely responses of students coming from high school. For their part, they gained insight into what we as a university community expect from students in our classes. The two Teachers-in-Residence differed in their contributions to the class, and in what they took away. One played a very active and direct role in teaching the class and brought in many materials to use, such as videos, which were not standard fare at Colorado State University. The other was less active directly but devised 50 or more activities that could be used in both high school and university settings. Both appreciated the professional development work with physics faculty members while increasing their depth of understanding and updating their content knowledge. They both helped me understand how the K-12 State Standards are applicable to physics courses, and at the same time then, saw the latest content and areas of emphasis at the university level. They were glad to develop new relationships and alliances with university personnel. In summary the two Teachers-in-Residence who were involved with my physics classes returned to the public school system with a greater sense of satisfaction and dedication to the development of relationships between $K-12$ teachers and higher education faculty. Upon returning to the public school system, they provided professional development training to other teachers on new content updates based on the research they observed while working with higher education faculty, as well as ideas on how to better link K-12 courses to introductory physics courses at the university. They also served as cooperating teachers for our student teachers, thus promoting the ideals of the reformed classroom. They leave a legacy of improved instructional strategies within undergraduate classrooms, and continue to provide a network at the local level for $K-12$ reform."

\section{Targeted Science and Mathematics Courses}

Central to the project's activities was the restructuring of targeted courses and their instructional approaches. The appropriate sections of the first-year introductory science and mathematics courses were redeveloped to promote active learning, preferably in an integrated lecture and laboratory format. The redesigned 
courses encouraged less reliance on the authoritarian, teacher-dominated, transfer model of science instruction and require a more spontaneous interchange of ideas. Also, the ubiquitous availability of laboratory equipment enabled students to discover relationships, as well as confirm them. Other changes in instructional strategies included bringing more inquiry-based, student-centered experiences into lecture sections through cooperative learning and peer-coaching techniques, enhancing learning using technology and other successful delivery systems aimed at actively engaging students.

Again, Professor Kern reflects:

"Introductory courses pH 121 and pH 122 are algebra-based with a laboratory component, and students who take them come from a wide variety of disciplines, with many from the biological sciences. The courses are recommended for preservice science teachers, although some prospective physics and mathematics teachers take a calculus-based course. Because students who enroll in the pH $121 / 122$ series come from very diverse backgrounds, often with little prior exposure to physics, these courses require the greatest degree of in-class explanation, demonstration, and motivation. They also are appropriate for modeling behaviors we wish future teachers to adopt-namely, an integrated lecture-laboratory approach based on understanding the material and problem solving, rather than a more traditional approach emphasizing rote memorization and application. This paper will further describe some observations about teaching an integrated lecture, laboratory, and recitation class in an 'Experiential Learning Studio' environment."

Classes met for $21 / 2$ hours, twice a week. The classroom was arranged with 24 desks clustered in groups of four, each forming an octagon with students seated on the inside. Students had their own space, yet there was an easy flow to interactions among members of each cluster and free flow for the instructor as well. Students took notes, solved in-class problems, performed laboratory experiments, and took exams at these desks, often acting cooperatively with their 'clustermates.' While the composition of clusters occasionally changed, in general they tended to be stable, with some groups continuing to operate more than two years after the class ended, and even maintaining contact after some members left campus. A good deal of camaraderie resulted from this use of cooperative learning, which promoted teamwork and 'information sharing.' Most class sessions consisted of a variety of activities, including a mixture of problem-solving demonstrations, and questions about homework from which further in-class questions developed-some emanating from students, many from the instructor. It was common to have a series of questions posed, escalating in difficulty and depth of understanding. As the instructor, I was not at all reluctant to make an occasional 
class quite intense. During these sessions, attention was highly focused and students gained a great deal from the concentrated emphasis on concepts and immediate application to practical problems they were asked to comment on and solve.

From student feedback, we can see the importance of addressing the kinesthetic component of learning for those students who have had less experience than others. The more closely students can tie experience to concepts or theory the greater their understanding of the subject matter. Importantly this models the inclass behavior we wish preservice science teachers to adopt for their core teaching. Facilitating this in a cooperative and participatory-environment brings us closer to approaching true facilitation of learning. Student response was overwhelmingly positive to the new initiatives. Over 80 percent of the class thought that having enough class time to answer questions was 'very-to-extremely' helpful, and 95 percent also agreed that the course was intellectually challenging."

\section{Science-Methods Courses}

General Methods of Teaching and Science Methods were combined into one two-semester course and was team-taught by science and mathematics faculty, education faculty and the TIR. The course utilized innovative (and tested) teaching methods, which are student-centered and inquiry-based. Including in-depth discussions of state and national content Standards, techniques for effective classroom management, skills in curriculum development and planning, and experience in inquiry-based and constructivist theory and practice in teaching and learning (constructivist methods emphasize the active engagement of the student in the learning process and recognizes the importance of prior knowledge for new learning). Hands-on experiences followed by structured reflection about what the student observed and what can be inferred and the infusion of science content was a significant part of the course. This course enabled preservice teachers to teach their future students to do science, which includes how to encourage scientific habits of mind. Integrated into this course was an on-going study of issues relating to equity and diversity. Students were expected to understand and practice research-based strategies for overcoming the educational barriers experienced by women and minority students in their study of science.

\section{Field-Based Experiences}

The quality of field experiences of future teachers was a central concern of the project. Contact between the campus program and teachers in the local schools were strengthened to establish a cadre of reform-minded cooperating teachers who would receive and help prepare the preservice teachers. Initially, outstanding teachers and later former TIRs served as cooperating teachers for new student teachers whenever possible. Ideal practices included following two years of supervised practicum activities (observations and classroom aides) in local K-12 
schools with monthly seminars given by the supervising team (the education specialist and the science or mathematics faculty). The student had occasional school visits by faculty during the first year of employment (the induction year) for inschool coaching, evaluating, mentoring and other supportive activities.

\section{Evaluation}

An external evaluation team was hired to provide evaluation in the form of accountability (formative implementation evaluation), feedback (formative progress evaluation) and outcomes (summative evaluation). To provide evidence of how well the goals of the project have been realized, the external evaluation team determined the answers to certain effectiveness questions concerning each of the components:

- How effective and long-term was the collaboration between the science and mathematics departments and the schools of education at CSU and the other sites?

- How many courses were redesigned, revised and institutionalized at each site?

- How many faculty were involved during the project's funding and how many continued to be involved after the external support was completed?

- What significant unintended impacts did the project have on the university environment?

- How many teachers received their degree/ certification? Where did they go?

- Did the project make a significant difference in the teaching skills of the graduates?

- Was there a positive difference in the students' attitudes and understandings in science and mathematics because of the graduates' training?

Professor Kern attempted to quantify his evaluation:

"The value of utilizing new strategies and methods, however, is measured by how well students learn. The first exam given to the initial class of 23 students was identical to the one given to the large, traditional lecture section of 485 students. My section grades averaged 60 percent, compared with the large section's 55 percent. These results were gratifying, since they indicated the populations were close to equivalent. On the next test, we decided to go to a nontraditional method of assessment, rather than using the multiple-choice method that was used for the first examination. However, we did include two questions on the second examination for our class that was used by the traditional section. The traditional section averaged 82 percent and 62 percent, compared with our class section's average of 96 percent for the two questions. We concluded that the conceptual emphasis used in our class did not pose a barrier to solving 'normal' types of questions. During 
the course of the year we could see $C$ - and even $D+$ students performing at a $C+$ and $B$ - level. Students attributed some of their increased understanding to doing 'hands-on' work as they were exploring and discussing concepts to actually seeing and knowing physics. We saw each cluster sharing and interchanging responsibilities. Gratifyingly, female students actively participated, and often assumed leadership roles. The structure also allowed team members to respond quickly to errors."

\section{The New Project-PhysTEC}

Recently, The American Physical Society (APS), in partnership with the American Association of Physics Teachers (AAPT) and the American Institute of Physics (AIP), submitted a proposal to the National Science Foundation (NSF) and to the Fund for the Improvement of Postsecondary Education (FIPSE) to dramatically improve the preparation of physics and physical science teachers nationwide. This project will increase the role of physics departments, in collaboration with education departments, to create more and better-prepared future teachers. Over the next five years, NSF/FIPSE will enable the Physics Teacher Education Coalition (PhysTEC) to be established with an initial membership of more than 25 universities and colleges that share an increasing interest in revising their program in teacher preparation.

The Coalition, through the leadership and assistance of the physics professional societies, will provide professional development for participating faculty and a vehicle for dissemination and research. PhysTEC will build on the experiences at CSU and other exemplary models that have documented their best practices. Although PhysTEC builds on components of the CSU experience, it transforms and inverts the strategy from a focus on several science and mathematics disciplines at a single geographical site to that of the nationwide reform of a single discipline (physics) aimed at a large number of college and university sites.

The Coalition will consist of three levels of institutional involvement. Six to eight of the institutions within the coalition will be selected as "Primary Program Institutions" (PPIs) and will be substantially supported by other external funders. They will engage in creating, describing and evaluating a set of model programs that are flexible in nature but will undertake some specific elements of programmatic change. Other schools with significant track records in teacher preparation will serve as "Resource Institutions" (RIs) that will be supported to consult and offer professional development advice and experience to the PPIs. The last group of institutions has demonstrated interest but is presently not involved in teacherpreparation programs. The involvement of the professional societies will make the coalition possible by providing access to the members of the broad physical-science community through the APS/AAPT leadership, committees, national meetings and conferences, workshops, and publications, and to those who can influ- 
ence policy regarding teacher preparation.

APS/AAPT/AIP have identified preservice (prospective) teacher preparation as a key issue for the physics community. To this purpose the three organizations recently approved a joint statement in which they "urge the physics community, specifically physical science and engineering departments and their faculty members, to take an active role in improving the preservice training of physics/science teachers." These societies now recognize a responsibility to assist physics departments and their faculty in developing strategies and implementing changes that allow them to constructively respond to this challenge.

As the focusing effort of PhysTEC, each of the PPIs will develop and implement a model program of study uniquely suited to their institution. The models will be informed by successful elements from previous projects emphasizing science and mathematics preparation for teachers. The PPIs will, in collaboration with PhysTEC staff members and each other, establish and publish guidelines to facilitate other institutions' adapting, implementing and evaluating these models. The PPIs, as models, will be expected to implement each of the following program elements in a productive manner that best suits their institutional environment.

- A long-term, active collaboration between the physics department, the school or department of education, the local two-year colleges and the local school community

- A productive TIR program as a "reality check" for reform

- The redesign of content and pedagogy for targeted physics courses by physics faculty based on results from physics education research and utilizing appropriate interactive technologies

- The integration of learning theory, teaching methods and physics content through revised and team-taught education science-methods courses

- The participation of physics faculty in the assignment and supervision of practicum and student teaching experiences

The selection of PhysTEC PPIs will be based on the individual institution's

1. commitment to become actively involved with teacher preparation reform as demonstrated by their degree of effectiveness (success) with previous efforts,

2. readiness to work in collaboration with faculty from the school of education,

3. degree of enthusiasm to model good teaching practices and their capacity to document their work and serve as a model for others within the higher education community,

4. willingness to shift some of their own resources toward PhysTEC and

5. capability for program institutionalization. 
Joining the efforts of APS/AAPT/AIP provides a unique opportunity for leadership, consultation and technical assistance through a single discipline that can encourage collaborations between departments of physics and education to implement and refine changes. There is preliminary evidence that an effort to improve the physics and physical-science education of elementary and secondary preservice teachers can contribute to the general revitalization of undergraduate science education. Physics departments that focus on providing good models in their introductory courses for preservice teachers will learn to adapt their efforts to improve the teaching and learning for all students.

During the academic year, teams of physics and education faculty (including department heads) from the PPIs will visit the campuses of the RIs. During the following summer, a conference and workshops will be held for all participants (plus newly interested institutions) led by the RI faculty and the PhysTEC staff to share, reinforce and develop strategic plans for the project implementation phase. Then PPIs will be expected to implement and institutionalize the program elements in a manner that best suits their institutional environment.

\section{References}

1. National Science Foundation, 1996.

2. ACE, 1999. 